7. Reprod. Fert. (1973) 34, 343-346

\title{
EFFECTS OF STRESS ON PREGNANCY IN THE RAT*
}

\author{
JEAN S. EUKER AND GAIL D. RIEGLE \\ Endocrine Research Unit, Michigan State University, East Lansing, \\ Michigan 48823, U.S.A.
}

(Received 20th June 1972)

Although stress or injections of ACTH or adrenal glucocorticoids have been associated with impaired reproductive performance in many species, the mechanisms by which these treatments affect reproduction remains obscure. Previous studies have indicated that stress may influence several stages of the normal reproductive process. Rowell (1970) reported increased follicular phase length and longer menstrual cycles following stress in baboons, and Hagino, Watanabe \& Goldzieher (1969) found that stress, ACTH or glucocorticoids could block PMSG-induced ovulation in rats. Adrenocortical activation in the pre-implantation phase has also been reported to inhibit fertility. Bruce (1967) showed that the stress of a strange male introduced to mated female mice resulted in a return to oestrus without apparent luteal function and Yang, Yang \& Lin (1969) found that although ACTH injection in the preimplantation phase did not alter the time interval required for ova to enter the uterus in rats, the number of implantations was reduced. On the other hand, Arvay (1967) and Zondek \& Tamari (1967) both reported increased luteal tissue and uterine weights which presumably reflected increased luteal secretions in stressed rats and rabbits. Stress or increased adrenal corticoids have been associated with increased embryo loss following implantation in sheep (Howarth \& Hawk, 1968) and rats (Arvay, 1967; Zondek \& Tamari, 1967; Yang et al., 1969). Although there have been numerous observations of stress effects on reproduction in mammals, the work is characterized by inconsistent and often directly conflicting observations. The current study concerns the effects of chronic restraint stress on the numbers of fertilized eggs which implant and on their subsequent development in the rat.

Four separate groups of eight regularly cycling, 7- to 9-month-old virgin Long-Evans rats were subjected to $2 \mathrm{hr}$ of restraint stress achieved by securing the rats' limbs to a countertop with the animal in the supine position (1) for 3 days before mating, (2) on Days 1 to 5 of pregnancy, (3) on Days 5 to 12 of pregnancy or (4) on Days 12 to 20 of pregnancy. The 2-hr restraint treatment was administered between 08.30 and 11.30 hours in all groups. The number of fertilized eggs implanting and the effect of the treatment regimens on early embryo development was determined by counting the number of fetuses in the uterus following laparotomies on Days 8 and 14 of pregnancy. Litter size and weight were measured at birth and at 7,14 and 21 days of age. The group stressed before mating received their first of 3 consecutive days of restraint on

* Michigan Agricultural Experiment Station Journal Article Number 5965. 
Day 1 of dioestrus of the cycle before their intended mating. The rats were caged with males and vaginal smears were taken daily. The day spermatozoa were detected in the vaginal smear was designated Day 1 of pregnancy. The females of all groups were isolated from the males on Day 1 of pregnancy. The litter sizes of the stressed groups were compared to those of two control groups; in one of these, the rats received no treatment throughout pregnancy and in the other, the rats were subjected to laparotomies on Days 8 and 14 of pregnancy.

The effect of the surgical stress of the laparotomies and the restraint stress regimens is illustrated in Text-fig. 1. The mean litter sizes of the rats in the untreated group and of those in the group subjected to two laparotomies during pregnancy were not different, indicating that the laparotomies did not impair normal pregnancy. The litter size of the rats in the experimental groups subjected to various restraint stress regimens were compared to the average litter size of the rats subjected to laparotomy in the control group.

Restraint stress before ovulation and mating did not affect litter size, but the expected oestrous vaginal smear and mating in this group was delayed for an average of 3 days. This suggests that $2 \mathrm{hr}$ of restraint stress administered during dioestrus was capable of blocking the cyclic release of gonadotrophins necessary for oestrogen secretion and ovulation. The increase in litter size from Days 8 to 14 of pregnancy in this group was due to an apparent delayed implantation in one rat. In this animal, no fetuses were observed in the uterus on Day 8 of pregnancy, fetuses which were smaller than normal were present on Day 14 and the rat littered on the 26th day after mating.

The effects of the restraint stress regimens during pregnancy were qualitatively similar. The greatest effect of stress on reproduction occurred during the time of the chronic stress administration. Embryonic mortality in the stressed rats was characterized by an 'all or none effect'; either the rats lost their entire litter after exposure to the stress or they retained and give birth to a litter of normal size. In the group stressed from Days 1 to 5 of pregnancy, three of the eight rats did not have implanted fetuses on Day 8 of pregnancy and by Day 14, only four of the eight rats had fetuses. Stress from Days 5 to 12 of pregnancy resulted in embryonic mortality in five rats between Days 8 and 14 after mating. Greatest fetal loss in the group exposed to stress from Days 12 to 20 of pregnancy occurred in the interval between the second laparotomy and birth. Of the eight rats in this group, only three produced normal litters, two delivered dead fetuses at term and three rats reabsorbed their uterine contents. Two young from the group stressed between Days 12 and 20 of pregnancy were hydrocephalic and did not survive beyond 40 days of age. This observation concurs with Arvay (1967) and others who have shown a high incidence of fetal malformations associated with normal stress.

In previous studies, we have shown that restraint stress results in maximal activation of adrenocortical secretions (Riegle, 1973). The data from the current study suggest that stress of this intensity can interfere with the reproductive process at several stages. The effect of each of the treatments seemed to be restricted to the period of stress administration. Further studies are needed to elucidate the mechanisms of action of stress on pregnancy. The ability of 
Control litter Nos

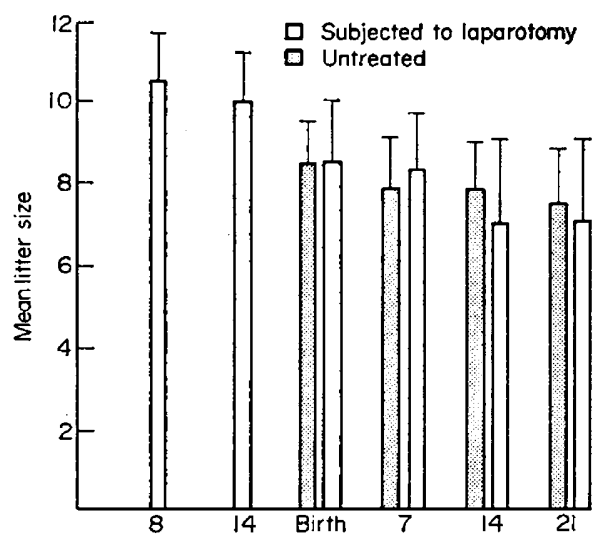

Stress before mating

Stress Days 5 to 12
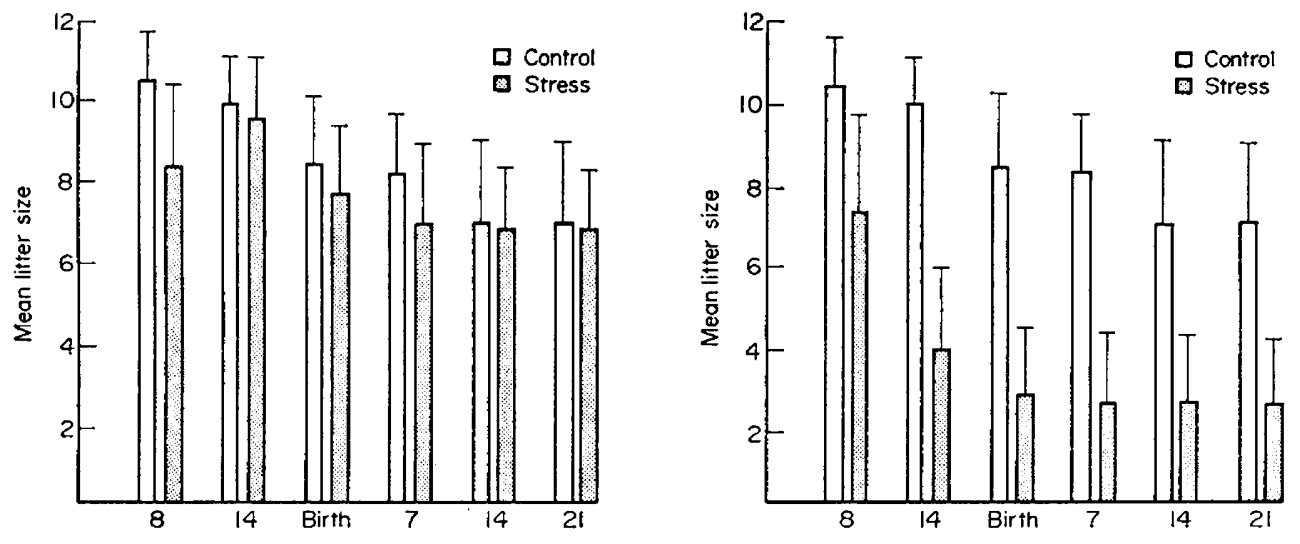

Stress Days 1 to 5

Stress Days 12 to 20
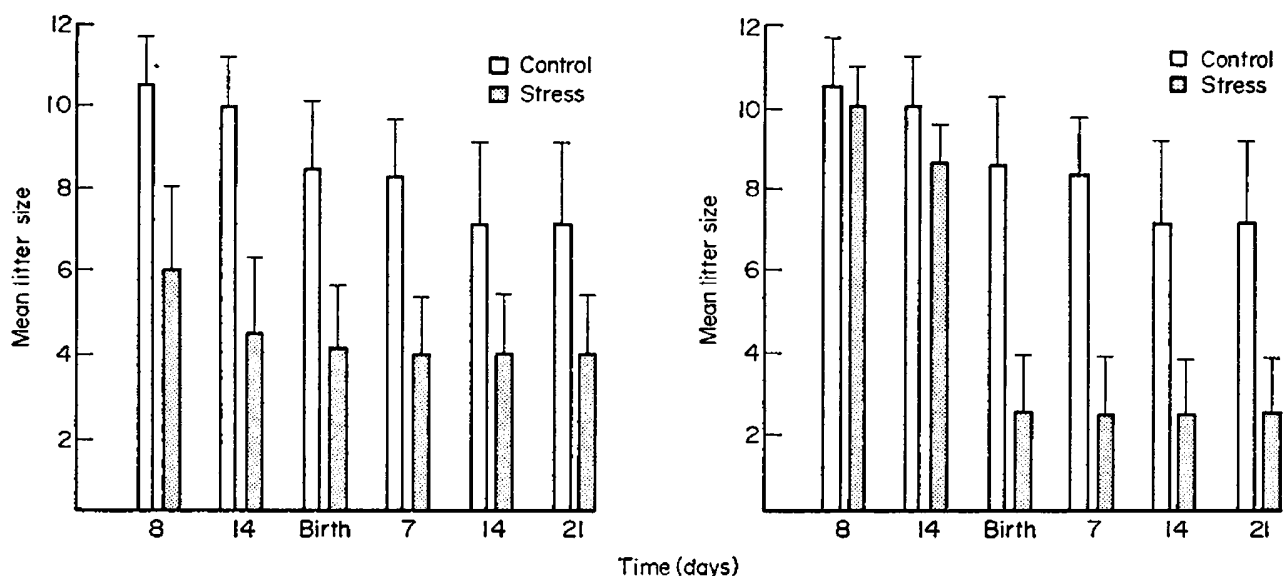

TexT-Fig. 1. The effect of stress on litter size. Mean litter size and standard errors (vertical bars) in a control group and four groups of rats subjected to chronic restraint stress for 2-hr periods (1) for 3 days before mating, and on (2) Days 1 to 5, (3) Days 5 to 12, and (4) Days 12 to 20 of pregnancy. Litter size was determined at laparotomy on Days 8 and 14 of pregnancy. Live young were counted at birth and on Days 7,14 and 21 following delivery. 
stress to interrupt reproductive processes at several stages suggests that the mechanism of action could include alterations in gonadotrophin secretions, luteal or placental secretions or uterine blood flow.

This work was supported in part by NSF Grant No. GB 8687 .

\section{REFERENCES}

ARvay, A. (1967) Effects of exteroceptive stimuli on fertility and their role in the genesis of malformations. Ciba Fdn Study Grps, 26, 20.

BRUCE, H. M. (1967) Effects of olfactory stimuli on reproduction in mammals. Ciba Fdn Study Grps, 26, 29.

Hagino, N., Watanabe, M. \& Goldziener, J. W. (1969) Inhibition by adrenocorticotropin of gonadotrophin-induced ovulation in immature female rats. Endocrinology, 84, 308.

HowarTh, B., JR \& HAWK, H. W. (1968) Effect of hydrocortisone on embryonic survival in sheep. 7. Anim. Sci. 27, 117.

RiEgLe, G. D. (1973) Chronic stress effects on adrenocortical responsiveness in young and aged rats. Neuroendocrinology, 11, 1.

Rowell, T. E. (1970) Baboon menstrual cycles affected by social environment. F. Reprod. Fert. 21, 133.

YANG, W. H., YANG, W. P. \& LIN, L. L. (1969) Interruption of pregnancy in the rat by administration of AGTH. Endocrinology, 84, 1282.

ZonDeK, B. \& TAMARI, I. (1967) Effects of auditory stimuli on reproduction. Ciba Fdn Study Grps, 26, 4. 